\title{
Penerapan Metode Question Student Have untuk Meningkatkan Aktivitas Belajar Siswa pada Mata Pelajaran Ilmu Pengetahuan Alam di Kelas V Sekolah Dasar Negeri 006 Sungai Buluh Kecamatan Singingi Hilir Kabupaten Kuantan Singingi
}

\author{
Inggit Nawangsih ${ }^{1}$ Melly Andriani ${ }^{2}$ \\ 1,2Program studi pendidikan guru Madrasah Ibtidaiyah, Universitas Islam Negeri Sultan \\ Syarif Kasim Rian \\ e-mail:inggit.nawangsib01@gmail.com
}

\begin{abstract}
Students on natural science subjects through the application of the question student have method in class V of 006 Sungai Buluh State Primary School Singingi Hilir District Kuantan Singingi District. This research is motivated by the low student learning activities, including the lack of student participation to ask questions when given the opportunity to ask questions, only some students answer questions from the teacher, and only some students do the assignments given by the teacher. This research is a classroom action research, as The subjects in this study were 1 teacher and 24 fifth-grade students of 006 Sungai Buluh Public Elementary School, Singingi Hilir District. The object in this study is the question student has method and learning activities. This research was conducted in two cycles, each cycle having two meetings. Data collection techniques used in this study were observation and documentation. While the data analysis technique used is descriptive qualitative analysis. Based on the results of research and data analysis, student learning activities in natural science learning before the action of student learning activities are only $53 \%$ or are in the low category. After taking action learning activities in the cycle of $60 \%$ with enough categories in the second cycle student learning activities increased to $84 \%$ with very good categories. So it can be concluded that through the application of the question student have method can increase student learning activities in natural science subjects in class V 006 Sungai Buluh State Primary School Singingi Hilir District Kuantan Singingi District.
\end{abstract}

Kata kunci: Learning Activities, Question Student Have, and Natural Sciences.

\section{PENDAHULUAN}

Belajar memerlukan aktivitas. Pada prinsipnya belajar adalah berbuat, berbuat untuk merubah tingkah laku dalam bentuk melakukan kegiatan. Tidak ada belajar tanpa melakukan aktivitas, itulah sebabnya aktivitas merupakan prinsip atau asas yang sangat penting didalam interaksi belajar mengajar. Bagaimana bisa seseorang dikatakan belajar jika tanpa melakukan aktivitas, karena belajar merupakan tahapan perubahan seluruh 
tingkah laku individu yang relatif menetap sebagai hasil pengalaman dan interaksi dengan lingkungan yang melibatkan proses kognitif.

Siswa dikatakan memiliki aktivitas apabila ditemukan ciri-ciri perilaku seperti bertanya kepada guru atau siswa lainya, mengerjakan tugas yang diberikan oleh guru, menjawab pertanyaan, mencatat materi pelajaran yang diberikan, memperhatikan guru dan lain sebagainya. Aktivitas merupakan azas yang paling penting dalam interaksi belajar mengajar, karena belajar tanpa aktivitas tidak mungkin seseorang itu berhasil dalam belajar. Aktivitas belajar siswa adalah kegiatan seseorang yang mendominasi kegiatan proses pembelajaran, sehingga seseorang tersebut aktif bertanya, mempertanyakan dan mengemukakan.

Jhon Dewey (1998:33) mengemukakan pentingnya aktivitas belajar siswa dalam metode proyeknya dengan semboyan learning by doing (belajar dengan melakukan). Pada proses pembelajaran juga harus ada aktivitas, baik itu aktivitas mental maupun aktivitas fisik, karena jika pada proses pembelajaran tidak terdapat aktivitas maka tujuan akhir dari pembelajaran tidak akan tercapai. Maka dari itu pada setiap proses pembelajaran aktivitas sangat dibutuhkan dan sangat di pentingkan agar hasil atau tujuan akhir dari pembelajaran dapat tercapai dengan maksimal

Dalam buku Cooperatif Learning PAIKEM menjelaskan pembelajaran aktif yaitu: proses belajar dengan menempatkan peserta didik sebagai center stage performance, dengan proses pembelajaran yang menarik sehingga siswa dapat merespon pembelajaran dengan suasana yang menyenangkan. Sedangkan aktif adalah siswa atau peserta didik mampu dan dapat bertanya, mempertanyakan, dan mengemukakan gagasan. Maka dari itu, berlangsungnya proses pembelajaran tidak terlepas dengan lingkungan sekitar atau tidak terbatas pada empat dinding kelas. Melainkan pembelajaran dapat terlaksana dengan pendekatan lingkungan menghapus kejenuhan dan menciptakan peserta didik yang yang cinta terhadap lingkungan sekitar (IPA).

IPA singkatan dari kata Ilmu Pengetahuan Alam merupakan terjemahan dari kata"natural science" secara singkat sering disebut "science". Natural artinya alamiah, berhubungan dengan alam, sedangkan science artinya ilmu pengetahuan. Jadi ilmu pengetahuan alam (selanjutnya disebut IPA atau Sains) secara harfiah dapat disebutkan sebagai ilmu tentang alam atau ilmu tentang peristiwa-peristiwa yang terjadi di alam.

\section{METODOLOGI}

Penelitian ini menggunakan metode penelitian tindakan kelas. Subjek dalam penelitian ini adalah satu orang guru kelas dan siswa kelas V Sekolah Dasar Negeri 006 Sungai Buluh Kecamatan Singingi Hilir Kabupaten Kuantan Singingi tahun 2018/2019 dengan jumlah siswa sebanyak 24 orang, 11 siswa perempuan dan 13 siswa laki-laki. Sedangkan yang menjadi objek penelitian ini adalah meningkatkan aktivitas belajar siswa melalui metode question student have.

\section{Observasi}

Observasi mencakup prosedur pengumpulan data tentang proses dan hasil implementasi tindakan yang dilakukan. Observasi menggunakan lembaran observasi yang dilakukan pada saat proses pembelajaran berlangsung. Observasi pada penelitian ini 
dilakukan oleh dua orang observer. Adapun yang diamati dalam penelitian ini adalah aktivitas belajar siswa, aktivitas siswa dan aktivitas guru selama kegiatan belajar mengajar.

Wawancara

Dalam penelitian ini peneliti mengadakan wawancara langsung dengan guru mata pelajaran Pendidikan Ilmu Pengetahuan Alam yang mengajar di Sekolah Dasar Negeri 006 Sungai Buluh Kecamatan Singingi Hilir Kabupaten Kuantan Singingi. Wawancara ini bertujuan agar kesalahpahaman atau minimnya ilmu peneliti akan terjawab dan hasilnyapun bisa dipertanggung jawabkan. Waktu wawancara dilaksanakan diluar jam pelajaran tepatnya pada waktu jam istirahat.

Dokumentasi

Dokumentasi ini diperoleh dari pihak-pihak yang terkait, seperti kepala sekolah untuk memperoleh data tentang sejarah dan perkembangan sekolah, data-data sarana dan prasarana sekolah, keadaan siswa dan guru disekolah, silabus, RPP, maupun nilai yang diperoleh sebelum dan sesudah digunakan metode question student haveatau dengan mendokumentasikan dalam bentuk gambar/foto pada saat dilaksanakan penelitian.

\section{HASIL DAN PEMBAHASAN}

\section{Hasil Penelitian}

\section{Perencanaan Tindakan}

Tahap perencanaan ini dilakukan untuk mempersiapkan perangkat pembelajaran yang akan dilakukan. Adapun yang akan dipersiapkan adalah menyusun RPP dan mempersiapkan silabus sesuai dengan mata pelajaran yang akan diteliti. Kemudian mempersiapkan perlengkapan yang berhubungan dengan metode question student have. Terakhir adalah mempersiapkan format pengamatan atau lembar observasi aktifitas yang dilakukan guru dan siswa selama proses pembelajaran berlangsung dengan menerapkan metode question student have.

\section{Pelaksanaan Tindakan}

\section{Pertemuan pertama}

Pertemuan pertama dilaksanakan pada tanggal 09 April 2019 jam ketiga dan keempat. Pokok bahasan yang dibahas adalah mengelompokkan benda yang bersifat magnetis serta mengetahui kekuatan gaya tarik magnet dalam menembus beberapa benda. Kompetensi dasar yang akan dicapai adalah siswa mampu mendeskripsikan hubungan antar gaya, gerak dan energi melalui percobaan (gaya magnet). Sedangkan indikator yang ingin dicapai adalahsiswa mampu mengelompokkan benda yang bersifat magnetis serta menunjukkan kekuatan gaya magnet dalam menembus beberapa benda melalui percobaan. Aktivitas guru melalui metode question student have digambarkan pada kegiatan awal, kegiatan inti, dan kegiatan akhir proses pembelajaran.

Kegiatan awal diklaksanakan 10 menit yang diawali dengan memberikan salam dan mengajak siswa bedoa. Kemudian mengkondisikan siswa agar siap belajar dan mengkondisikan posisi duduk siswa. Kemudian guru memberikan apersepsi kepada siswa yang dengan mengajukan pertanyaan mengenai materi minggu (magnet) lalu dan mengaitkan materi yang akan dilakukan, selanjutnya guru menyampaikan tujuan pembelajaran yang akan dicapai oleh siswa. 
Kegiatan inti dilakukan \pm 50 menit, kegiatan ini diawali dengan guru menyajikan pembelajaran mengenai, menjelaskan pengertian gaya magnet danmengelompokkan bendabenda yang tidak dapat ditarik oleh magnet, dengan menggunakan gambar, lalu guru meminta agar siswa dalam kelas mengemukakan pendapatnya tentang gambar yang telah dilihatnya. Setelah itu guru membagi kelas mejadi 4 kelompok, dan tiap kelompoknya terdapat 6 orang siswa (posisi duduk melingkar searah jarum jam), guru membagikan sepotong kertas (kartu) kepada masing-masing siswa dan guru meminta siswa untuk menuliskan satu pertanyaan yang tidak diketahui oleh siswa pada lembar tersebut, langkah selanjutnya guru meminta siswa untuk memberikan kartu yang sudah diisi dengan pertanyaan kepada teman sebelahnya (searah jarum jam) lalu temannya diminta untuk membaca pertanyaan yang didapat dari teman sebelahnya dan memberikan tanda centang $(\sqrt{ })$ pada kartu bagian atas apabila pertanyaan tersebut dianggap penting dan ingin di ketahui jawabannya, ketika kartu pertanyaan tadi telah kembali kepada pemiliknya, siswa diminta untuk menghitung tanda centang $(\sqrt{ })$ yang ada pada kartunya, setelah mendapatkan kartu yang mendapatkan centang paling banyak guru memberikan respon dengan menjawab pertanyaan tersebut, ketika waktu tidak mencukupi maka guru mengumpulkan semua kertas yang tersisa (yang belum terjawab), besar kemungkinan akan dijawab di pertemuan-pertemuan selanjutnya

Kegiatan akhir dilakukan selama 10 menit, guru memberikan kesempatan kepada siswa untuk bertanya mengenai materi yang dipelajari.Pada kegiatan akhir siswa membuat kesimpulan pelajaran dan mengakhiri pelajaran dengan mengucapkan salam.

\section{Pertemuan Kedua}

Pertemuan kedua dilaksanakan pada hari selasa tanggal 11 April 2019. Dengan indikator memberi contoh penggunaan gaya magnet dalam kehidupan sehari-hari dan cara membuat magnet. Kegiatan awal dilaksanakan selama 10 menit yang diawali dengan guru mengucap salam, mengkondisikan siswa siap untuk belajar dan melakukan absensi siswa. Selanjutnya guru melakukan apersepsi dengan menanyakan apa materi pada pertemuan sebelumnya dan mengaitkan dengan pembelajaran yang akan dilakukan. Selanjutnya guru menyampaikan tujuan pembelajaran yang akan dicapai oleh siswa.

Kegiatan inti dilakukan \pm 50 menit, kegiatan ini diawali dengan guru menyajikan pembelajaran mengenai, menjelaskan pengertian gayamagnet dan mengelompokkan bendabenda yang tidak dapat ditarik oleh magnet, dengan menggunakan gambar, lalu guru meminta agar siswa dalam kelas mengemukakan pendapatnya tentang gambar yang telah dilihatnya. Setelah itu guru membagi kelas mejadi 4 kelompok, dan tiap kelompoknya terdapat 6 orang siswa (posisi duduk melingkar searah jarum jam), guru membagikan sepotong kertas (kartu) kepada masing-masing siswa dan guru meminta siswa untuk menuliskan satu pertanyaan yang tidak diketahui oleh siswa pada lembar tersebut, langkah selanjutnya guru meminta siswa untuk memberikan kartu yang sudah diisi dengan pertanyaan kepada teman sebelahnya (searah jarum jam) lalu temannya diminta untuk membaca pertanyaan yang didapat dari teman sebelahnya dan memberikan tanda centang $(\sqrt{ })$ pada kartu bagian atas apabila pertanyaan tersebut dianggap penting dan ingin di ketahui jawabannya, ketika kartu pertanyaan tadi telah kembali kepada pemiliknya, siswa diminta untuk menghitung tanda centang $(\sqrt{ })$ yang ada pada kartunya, setelah mendapatkan kartu yang mendapatkan centang paling banyak guru memberikan respon dengan menjawab pertanyaan tersebut, ketika waktu tidak mencukupi maka guru mengumpulkan 
semua kertas yang tersisa (yang belum terjawab), besar kemungkinan akan dijawab di pertemuan-pertemuan selanjutnya.

Kegiatan akhir dilakukan selama 10 menit, guru memberikan kesempatan kepada siswa untuk bertanya mengenai materi yang dipelajari.Pada kegiatan akhir siswa membuat kesimpulan pelajaran dan mengakhiri pelajaran dengan mengucapkan salam.

\section{Tabel. IV. 1Keadaan Guru SDN 006 SungaiBuluh T.A \\ $2018 / 2019$}

\begin{tabular}{|c|c|c|c|c|c|c|}
\hline No & Nama/ nip & $\mathrm{L} / \mathrm{p}$ & Agama & $\begin{array}{l}\text { Gol/R } \\
\text { uang }\end{array}$ & Jenis Guru & Jabatan Guru \\
\hline 1 & $\begin{array}{l}\text { Tarwan, S.Pd. SD } \\
\text { NIP. } 196705101991031005\end{array}$ & $\mathrm{~L}$ & Islam & $\mathrm{IV} / \mathrm{A}$ & KEP. SD & Guru Pembina \\
\hline 2 & $\begin{array}{l}\text { Sakhri Rezki Putri, S.Pd } \\
\text { NIP. } 198705282019032002\end{array}$ & $\mathrm{P}$ & Islam & $\mathrm{IV} / \mathrm{A}$ & GR KLS & Guru Pembina \\
\hline 3 & $\begin{array}{l}\text { Sudirman, S.Pd.SD } \\
\text { NIP. } 196609151989081001\end{array}$ & $\mathrm{~L}$ & Islam & $\mathrm{IV} / \mathrm{A}$ & GR KLS & Guru Pembina \\
\hline 4 & $\begin{array}{l}\text { Suyatini, S.Pd.SD } \\
\text { NIP. } 197005021991122001\end{array}$ & $\mathrm{P}$ & Islam & IV / A & GR KLS & Guru Pembina \\
\hline 5 & $\begin{array}{l}\text { Indot, S.Pd.SD } \\
\text { NIP. } 197112011992032004\end{array}$ & $\mathrm{P}$ & Islam & $\mathrm{IV} / \mathrm{A}$ & GR KLS & Guru Pembina \\
\hline 6 & $\begin{array}{l}\text { Siti Khalimah, A.Ma } \\
\text { NIP. } 196304271992032002\end{array}$ & $\mathrm{P}$ & Islam & $\mathrm{IV} / \mathrm{A}$ & GR KLS & Guru Pembina \\
\hline 7 & $\begin{array}{l}\text { Junaidah, S.Pd.SD } \\
\text { NIP. } 196802032007012006\end{array}$ & $\mathrm{P}$ & Islam & $\mathrm{III} / \mathrm{A}$ & GR KLS & Guru Penata \\
\hline 8 & $\begin{array}{l}\text { Gustina, S.Pd.I } \\
\text { NIP. } 197008072008012035\end{array}$ & $\mathrm{P}$ & Islam & $\mathrm{I} / \mathrm{B}$ & GR KLS & Guru Pengatur \\
\hline 9 & Suprapti, S.Pd.SD & $\mathrm{P}$ & Islam & - & GR KLS & GTT \\
\hline 10 & Lili Rianti, S.Pd.SD & $\mathrm{P}$ & Islam & - & GR KLS & GT'T \\
\hline 11 & Siti Fatonah, S.Pd.SD & $\mathrm{P}$ & Islam & - & GR KLS & GTT \\
\hline 12 & Dewi Yana, S.Pd.SD & $\mathrm{P}$ & Islam & - & GR KLS & GTT \\
\hline 13 & Edi Kuswoyo, A.Ma.Pd.SD & $\mathrm{L}$ & Islam & - & GR KLS & GT'T \\
\hline 14 & Sudiyono, A.Ma.Pd.SD & $\mathrm{L}$ & Islam & - & GR KLS & GTT \\
\hline 15 & Moh Rafli & $\mathrm{L}$ & Islam & - & OPS & THS \\
\hline 16 & Sukisman, S.Pd.I & $\mathrm{L}$ & Islam & - & GR PAI & GTT \\
\hline 17 & Diah Nur Utami, S.Pd & $\mathrm{P}$ & Islam & - & GR KLS & GTT \\
\hline 18 & Ritas Aprianto, S.Pd & $\mathrm{L}$ & Islam & - & GR KLS & GT'T \\
\hline 19 & Dedi, S.Pd & $\mathrm{L}$ & Islam & - & GR PJOK & GTT \\
\hline
\end{tabular}

Sumber : Hasil Data April 2019

\section{Keadaan Siswa}

Siswa merupakan salah satu komponen kegiatan pendidikan di sekolah.Adapun keadaan siswa Sekolah Dasar Negeri 006 Sungai Buluh Kecamatan Singingi Hilir Kabupaten Kuantan Singingi. 


\section{Tabel. IV. 2Keadaan Siswa SDN 006 Sungai Buluh T.A $2018 / 2019$}

\begin{tabular}{ccccc}
\hline No & Kelas & $\begin{array}{c}\text { Laki- } \\
\text { laki }\end{array}$ & Perempuan & Jumlah \\
\hline 1 & I & 20 & 23 & 43 \\
2 & II & 21 & 20 & 41 \\
3 & III A & 13 & 17 & 30 \\
4 & III B & 15 & 15 & 30 \\
5 & IV & 25 & 28 & 53 \\
6 & V & 13 & 11 & 24 \\
7 & VI & 16 & 21 & 37 \\
Jumlah & & $\mathbf{1 2 3}$ & $\mathbf{1 3 5}$ & $\mathbf{2 5 8}$ \\
\hline
\end{tabular}

Sumber: Hasil Data April 2019

\section{Sarana dan Prasarana}

Disamping guru sebagai pendidik dan siswa sebagai anak didik sarana dan prasarana juga memegang peranan penting dalam menunjang tercapainya proses pembelajaran. Adapun sarana dan prasarana yang dimiliki oleh SDN 006 dapat dilihat pada tabel dibawah ini:

Tabel. IV. 3KeadaanSarana dan Prasarana SDN 006 Sungai Buluh T.A 2018/2019

\begin{tabular}{clcc}
\hline No & Sarana dan Prasarana & Jumlah Unit & Kondisi \\
\hline 1 & Ruang Kepala Sekolah & 1 & Baik \\
2 & Ruang Guru & 1 & Baik \\
3 & Ruang Kelas & 7 & Baik \\
4 & Musholla & 1 & Baik \\
5 & Perpustakaan & 1 & Baik \\
6 & Parkiran & 1 & Baik \\
7 & Kamar Mandi/ WC & 4 & Baik \\
8 & Alat Drum Band & 1 Set & Baik \\
9 & Seragam Drum Band & 1 Set & Baik \\
10 & Alat-alat olah raga & 1 Set & Baik \\
Sumber: Hasil Data April 2019 & &
\end{tabular}

\section{Observasi aktivitas guru}

Aktivitas guru yang diamati oleh obsever dalammenetapkan metodequestion student have, untuk lebih jelas dapat dilihat pada tabel berikut : 
Tabel.IV.5 Hasil Observasi Aktivitas Guru Siklus I Pertemuan pertama

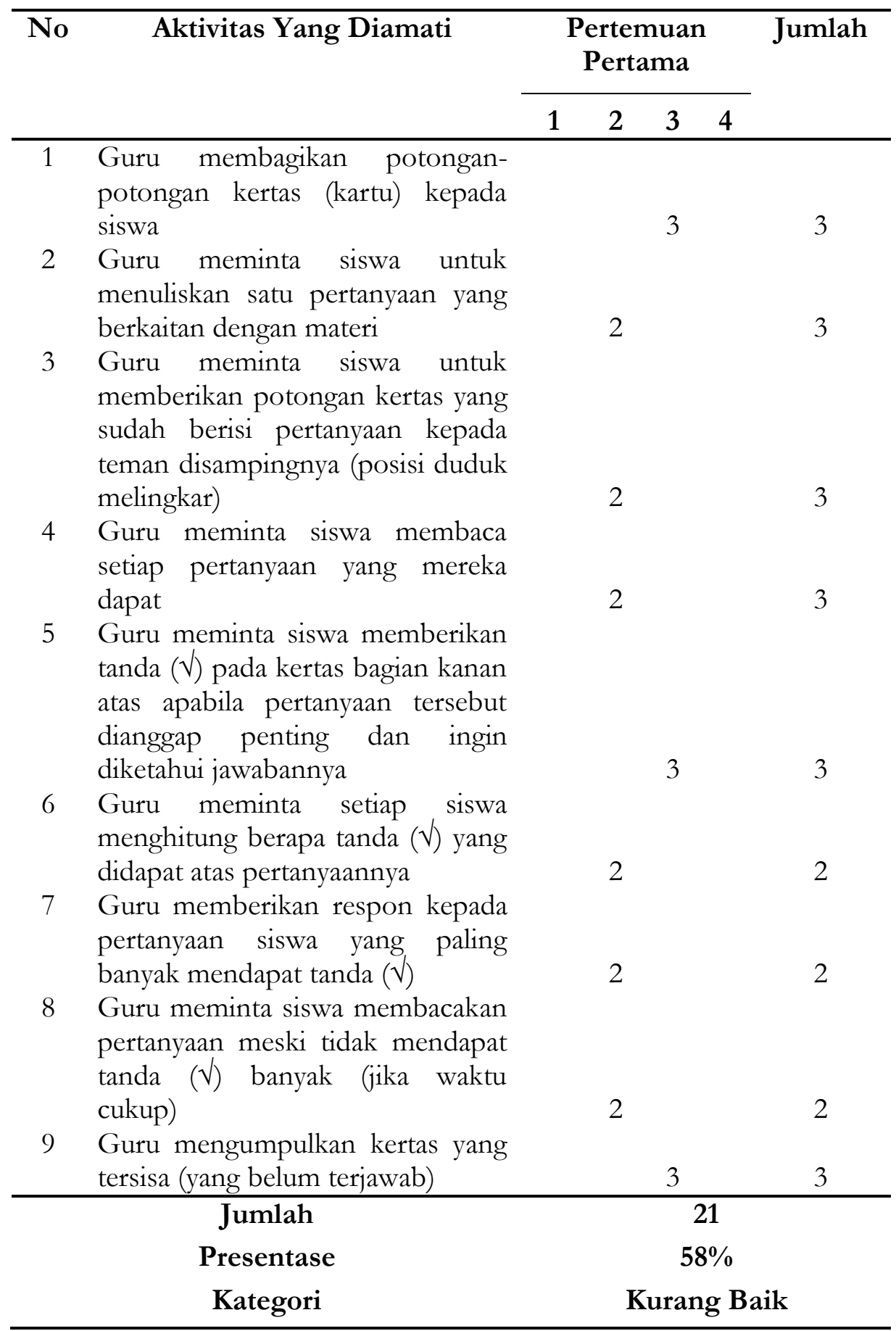

Sumber: Hasil observasi April 2019

Berdasarkan tabel IV.5 dapat dilihat bahwa aktivitas guru pada siklus I pertemuan pertama berjalan dengan kategori "Kurang Baik", hal tersebut dapat dibuktikan dengan perolehan persentase $58 \%$ dengan skor 21 . 


\section{Tabel.IV.6Hasil Observasi Aktivitas Guru Siklus I Pertemuan Kedua}

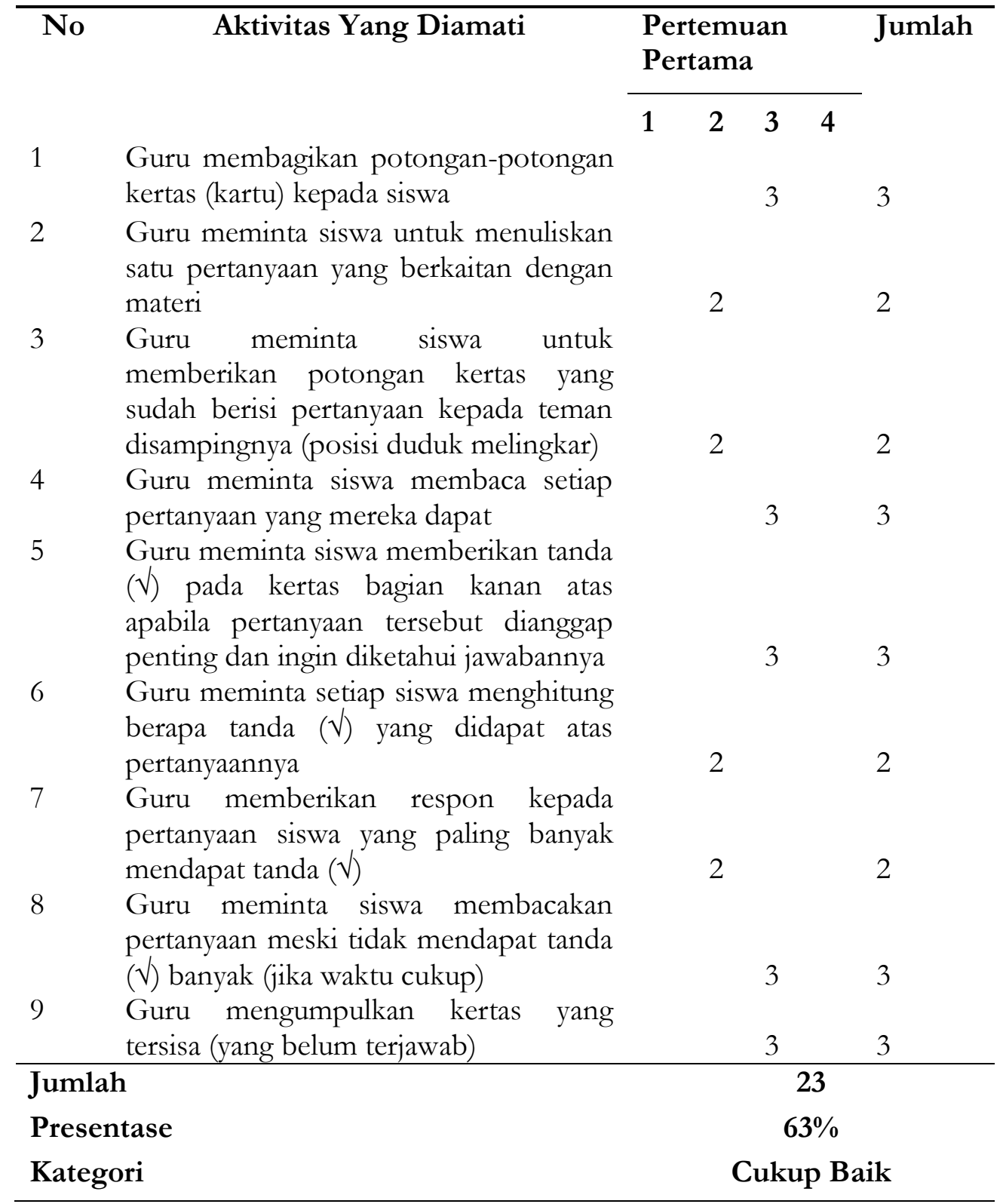

Sumber: Hasil observasi April 2019

Berdasarkan tabel IV.6 dapat dilihat bahwa aktivitas guru pada Siklus I pertemuan Kedua dapat berjalan lancar dengan kategori "Cukup Baik", hal tersebut dibuktikan dengan perolehan persentase 63\% dengan skor 23 .

Berdasarkan hasil observasi aktivitas guru Siklus I Pertemuan Pertama dan Kedua dapat dilihat sebagai berikut: 


\section{Tabel IV. 7Rekapitulasi Observasi Aktivitas Guru Siklus I pertemuan Pertama dan Kedua}

\begin{tabular}{|c|c|c|c|c|}
\hline \multirow[t]{2}{*}{ No } & \multirow[t]{2}{*}{ Aktivitas Yang Diamati } & $\begin{array}{c}\text { Pertemuan } \\
\text { I }\end{array}$ & $\begin{array}{l}\text { Pertemuan } \\
\text { II }\end{array}$ & \multirow[t]{2}{*}{$\begin{array}{l}\text { Rata- } \\
\text { rata }\end{array}$} \\
\hline & & Skor & Skor & \\
\hline 1 & $\begin{array}{l}\text { Guru membagikan potongan- } \\
\text { potongan kertas kepada siswa }\end{array}$ & 3 & 3 & 3 \\
\hline 2 & $\begin{array}{l}\text { Guru meminta siswa untuk } \\
\text { menuliskan satu pertanyaan yang } \\
\text { berkaitan dengan materi }\end{array}$ & 2 & 2 & 2 \\
\hline 3 & $\begin{array}{l}\text { Guru meminta siswa untuk } \\
\text { memberikan potongan kertas yang } \\
\text { sudah berisi pertanyaan kepada } \\
\text { teman disampingnya (posisi duduk } \\
\text { melingkar) }\end{array}$ & 2 & 2 & 2 \\
\hline 4 & $\begin{array}{l}\text { Guru meminta siswa membaca setiap } \\
\text { pertanyaan yang mereka dapat }\end{array}$ & 2 & 3 & 2,5 \\
\hline 5 & $\begin{array}{l}\text { Guru meminta siswa memberikan } \\
\text { tanda }(\sqrt{ }) \text { pada kertas bagian kanan } \\
\text { atas apabila pertanyaan tersebut } \\
\text { dianggap penting dan ingin diketahui } \\
\text { jawabannya }\end{array}$ & 3 & 3 & 3 \\
\hline 6 & $\begin{array}{l}\text { Guru meminta siswa menghitung } \\
\text { berapa tanda }(\sqrt{ }) \text { yang didapat atas } \\
\text { pertanyaanya }\end{array}$ & 2 & 2 & 2 \\
\hline 7 & $\begin{array}{l}\text { Guru memberikan respon kepada } \\
\text { pertanyaan siswa yang paling banyak } \\
\text { mendapat tanda }(\sqrt{ })\end{array}$ & 2 & 2 & 2 \\
\hline 8 & $\begin{array}{l}\text { Guru meminta siswa membacakan } \\
\text { pertanyaan meski tidak mendapat } \\
\text { tanda }(\sqrt{ }) \text { banyak (jika waktu cukup) }\end{array}$ & 2 & 3 & 2,5 \\
\hline 9 & $\begin{array}{l}\text { Guru mengumpulkan kertas yang } \\
\text { tersisa (yang belum terjawab) }\end{array}$ & 3 & 3 & 3 \\
\hline & Jumlah & 21 & 23 & 22 \\
\hline & Presentase & $58 \%$ & $63 \%$ & $61 \%$ \\
\hline & Kategori & Kurang & Cukup & Cukup \\
\hline & & Baik & Baik & Baik \\
\hline
\end{tabular}

\section{Observasi aktivitas guru}

Aktivitas guru yang diamati oleh obsever dalammenetapkan metodequestion student have, untuk lebih jelas dapat dilihat pada tabel berikut : 


\section{Tabel.IV.5 Hasil Observasi Aktivitas Guru Siklus I Pertemuan pertama}

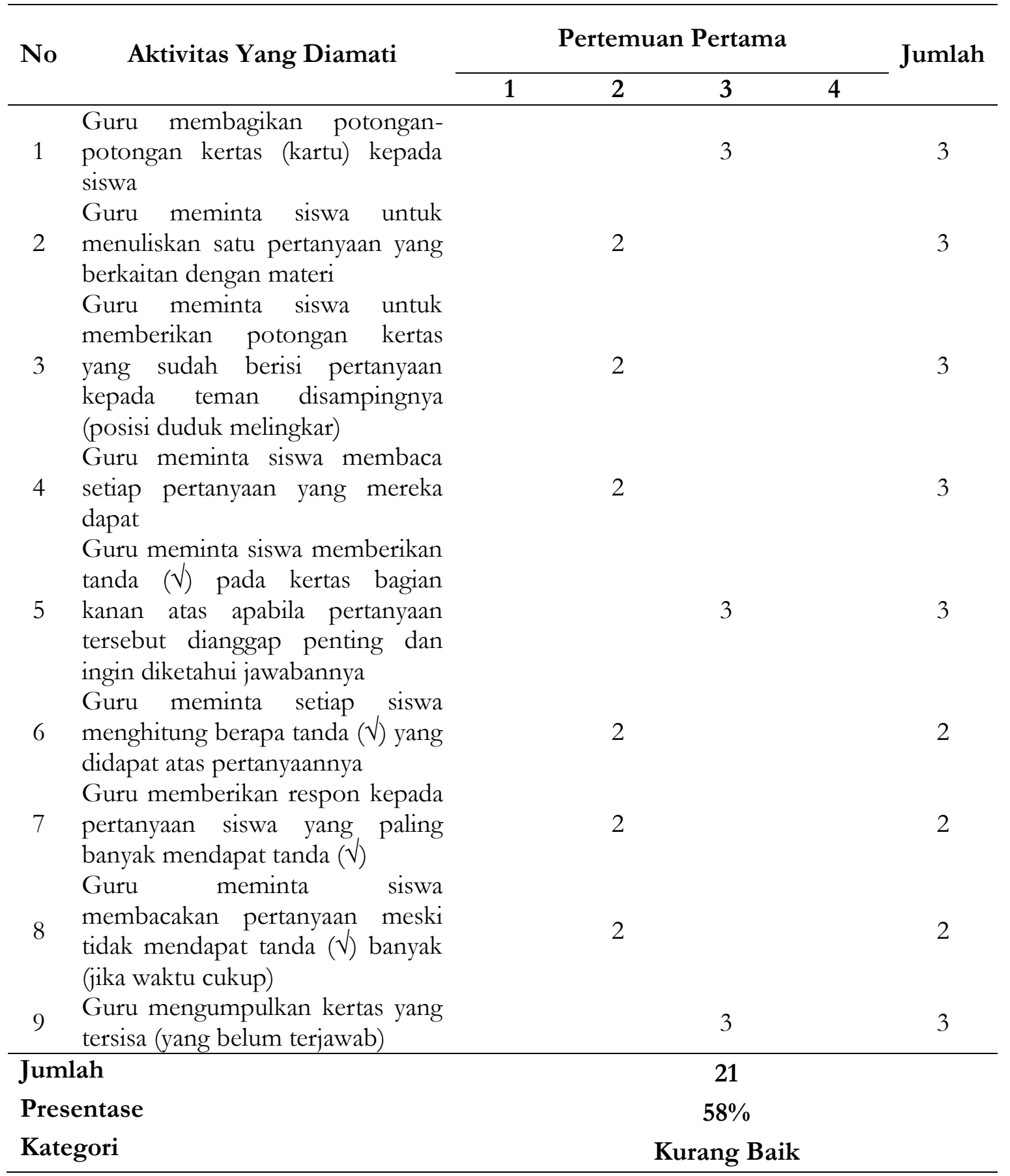

Sumber: Hasil observasi April 2019

Berdasarkan tabel IV.5 dapat dilihat bahwa aktivitas guru pada siklus I pertemuan pertama berjalan dengan kategori "Kurang Baik", hal tersebut dapat dibuktikan dengan perolehan persentase 58\% dengan skor 21 . 


\section{Tabel.IV.6Hasil Observasi Aktivitas Guru Siklus I Pertemuan Kedua}

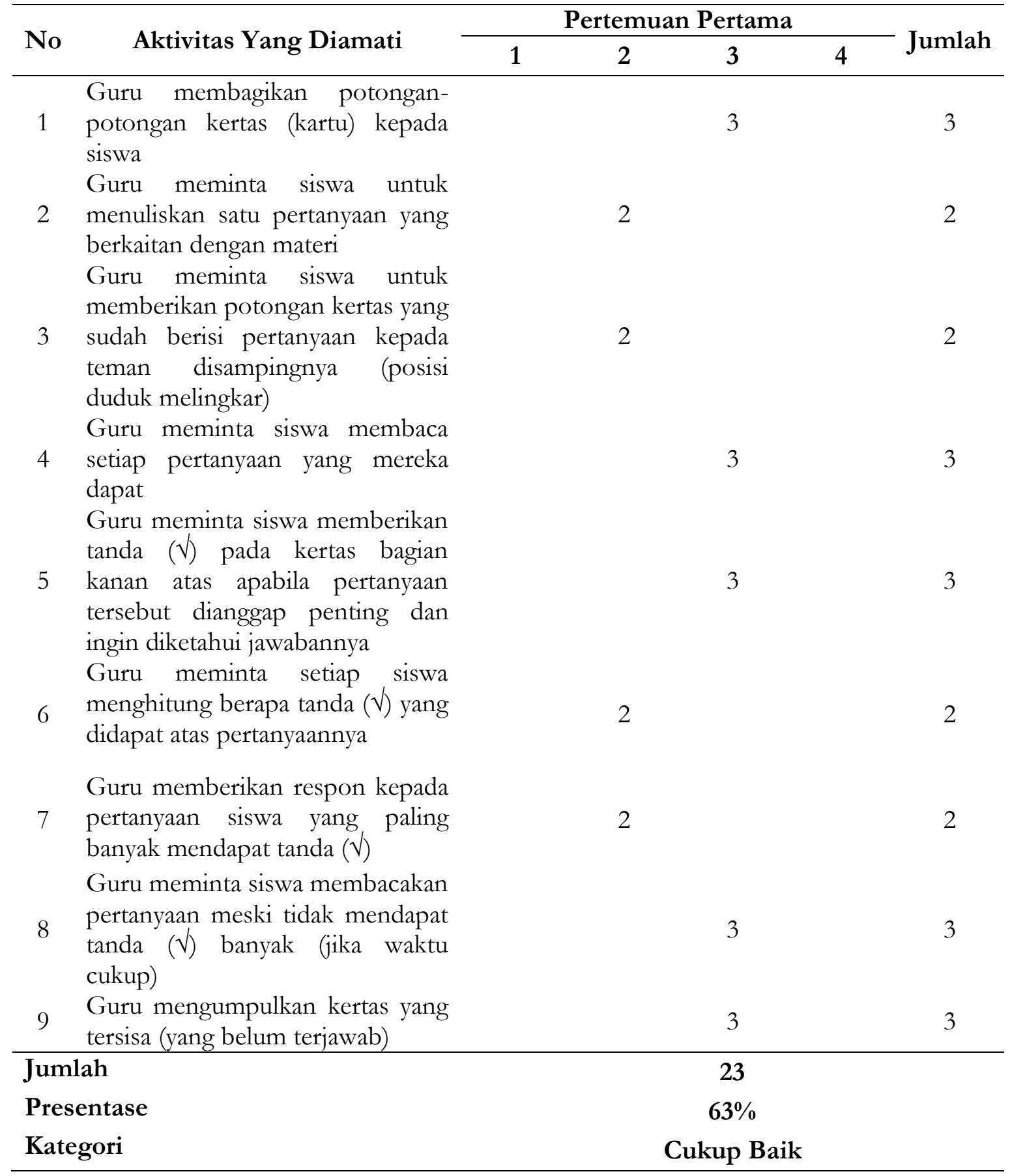

Sumber: Hasil observasi April 2019

Berdasarkan tabel IV.6 dapat dilihat bahwa aktivitas guru pada Siklus I pertemuan Kedua dapat berjalan lancar dengan kategori "Cukup Baik", hal tersebut dibuktikan dengan perolehan persentase 63\% dengan skor 23.

Berdasarkan hasil observasi aktivitas guru Siklus I Pertemuan Pertama dan Kedua dapat dilihat sebagai berikut: 


\section{Tabel IV. 7Rekapitulasi Observasi Aktivitas Guru Siklus I pertemuan Pertama dan Kedua}

\begin{tabular}{|c|c|c|c|c|}
\hline No & Aktivitas Yang Diamati & $\begin{array}{c}\text { Pertemuan } \\
\text { I } \\
\text { Skor }\end{array}$ & $\begin{array}{c}\text { Pertemuan } \\
\text { II } \\
\text { Skor }\end{array}$ & $\begin{array}{l}\text { Rata- } \\
\text { rata }\end{array}$ \\
\hline 1 & $\begin{array}{l}\text { Guru membagikan potongan-potongan } \\
\text { kertas kepada siswa }\end{array}$ & 3 & 3 & 3 \\
\hline 2 & $\begin{array}{l}\text { Guru meminta siswa untuk menuliskan satu } \\
\text { pertanyaan yang berkaitan dengan materi }\end{array}$ & 2 & 2 & 2 \\
\hline 3 & $\begin{array}{l}\text { Guru meminta siswa untuk memberikan } \\
\text { potongan kertas yang sudah berisi } \\
\text { pertanyaan kepada teman disampingnya } \\
\text { (posisi duduk melingkar) }\end{array}$ & 2 & 2 & 2 \\
\hline 4 & $\begin{array}{l}\text { Guru meminta siswa membaca setiap } \\
\text { pertanyaan yang mereka dapat }\end{array}$ & 2 & 3 & 2,5 \\
\hline 5 & $\begin{array}{l}\text { Guru meminta siswa memberikan tanda }(\sqrt{ }) \\
\text { pada kertas bagian kanan atas apabila } \\
\text { pertanyaan tersebut dianggap penting dan } \\
\text { ingin diketahui jawabannya }\end{array}$ & 3 & 3 & 3 \\
\hline 6 & $\begin{array}{l}\text { Guru meminta siswa menghitung berapa } \\
\text { tanda }(\sqrt{ }) \text { yang didapat atas pertanyaanya }\end{array}$ & 2 & 2 & 2 \\
\hline 7 & $\begin{array}{l}\text { Guru memberikan respon kepada } \\
\text { pertanyaan siswa yang paling banyak } \\
\text { mendapat tanda }(\sqrt{ })\end{array}$ & 2 & 2 & 2 \\
\hline 8 & $\begin{array}{l}\text { Guru meminta siswa membacakan } \\
\text { pertanyaan meski tidak mendapat tanda }(\sqrt{ }) \\
\text { banyak (jika waktu cukup) }\end{array}$ & 2 & 3 & 2,5 \\
\hline 9 & $\begin{array}{l}\text { Guru mengumpulkan kertas yang tersisa } \\
\text { (yang belum terjawab) }\end{array}$ & 3 & 3 & 3 \\
\hline \multicolumn{2}{|c|}{ Jumlah } & 21 & 23 & 22 \\
\hline \multicolumn{2}{|c|}{ Presentase } & $58 \%$ & $63 \%$ & $61 \%$ \\
\hline \multicolumn{2}{|c|}{ Kategori } & $\begin{array}{c}\text { Kurang } \\
\text { Baik }\end{array}$ & $\begin{array}{c}\text { Cukup } \\
\text { Baik }\end{array}$ & $\begin{array}{c}\text { Cukup } \\
\text { Baik }\end{array}$ \\
\hline
\end{tabular}

\section{KESIMPULAN}

Berdasarkan hasil penelitian dan analisis data dapat disimpulkan bahwa penerapan metode Question Student Have dapat meningkatkan aktivitas belajar siswa pada mata pelajaran Ilmu Pengetahuan Alam kelas V Sekolah Dasar Negeri 006 Desa Sungai Buluh Kecamatan Singingi Hilir Kabupaten Kuantan Singingi. Hal ini dapat dilihat bahwa aktivitas belajar Ilmu Pengetahuan Alam siswa sebelum tindakan hanya mencapai 53\% masih tergolong kategori "Rendah". Setelah dilakukan penelitian tindakan kelas pada siklus I, aktivitas siswa meningkat menjadi 60\% atau kategori "Rendah". Kemudian pada siklus II terjadi peningkatan menjadi 84\% atau kategori "Sangat Baik". Artinya indikator keberhasilan yang telah ditetapkan yaitu 75\% telah tercapai. 


\section{REFERENSI}

Hartono, dkk.(2008). PAIKEM Pembelajaran Aktif, Inovatif, Kreatif, Efektif Dan

Menyenangkan. Pekanbaru : ZANAFA PUBLISHING.

Masnur Muchlis.(2011). Melaksanakan PTK Itu Mudah. Jakarta: Bumi Aksara.

Mel Silbermen.(2009). Active Learning 101 Strategi Pembelajaran Aktif. Yogyakarta:Yappendis, Edisi Revisi.

E. Mulyasa.(2009). Praktik Penelitian Tindakan Kelas. Bandung: PT Remaja

Mohammad Uzer Usman.(1976). Upaya Optimalisasi KBM. Bandung: Remaja Rosdakarya.

Oemar Hamalik.(2011). Kurikulum dan Pembelajaran. Jakarta: Bumi Aksara.

Pat Hollingsword, dkk.(2008). Pembelajaran Aktif, Jakarta : PT Indeks.

http://Sondix. Blogspot.Com. Pengertian Aktivitas Menurut Para Ahli, Diakses pada tanggal 09 maret 2018.

Riduan.(2010). Skala Pengukuran Variabel-Variabel Penelitian. Bandung: Alfabeta.

Sardiman.(2011). Interkasi Dan Motivasi Belajar Mengajar. Jakart: Rajawali Pers.

Suharsimi Arikunto.(2009). Peneltian Tindakan Kelas. Jakarta: Bumi Aksara.

Sukma Erni, dkk.(2016). Penelitian Tindakan Kelas. Pekanbaru: Kreasi Edukasi.

Susilawati.(2013). Pembelajaran IPA di Madrasah Ibtidaiyah. Pekanbaru: Banteng Media. 